\title{
Factors associated with survival in small cell lung cancer: an analysis of real-world national audit, chemotherapy and radiotherapy data
}

\author{
Gavin S. Jones ${ }^{1}$, Aamir Khakwani ${ }^{1}$, Abigail Pascoe ${ }^{2}$, Karen Foweraker ${ }^{2}$, Tricia M. McKeever ${ }^{1}$, \\ Richard B. Hubbard ${ }^{1}$, David R. Baldwin ${ }^{1,3}$ \\ ${ }^{1}$ Division of Epidemiology and Public Health, University of Nottingham, Nottingham, UK; ${ }^{2}$ Department of Clinical Oncology, Nottingham \\ University Hospitals, Nottingham, UK; ${ }^{3}$ Department of Respiratory Medicine, Nottingham University Hospitals, Nottingham, UK \\ Contributions: (I) Conception and design: GS Jones, DR Baldwin, RB Hubbard, TM McKeever; (II) Administrative support: None; (III) Provision of \\ study materials or patients: GS Jones, RB Hubbard, DR Baldwin, TM McKeever; (IV) Collection and assembly of data: GS Jones, A Khakwani, TM \\ McKeever; (V) Data analysis and interpretation: All Authors; (VI) Manuscript writing: All authors; (VII) Final approval of manuscript: All authors. \\ Correspondence to: Dr. Gavin S. Jones, BMBS, PhD. Division of Epidemiology and Public Health, Clinical Sciences Building, Nottingham, UK. \\ Email: gavin.jones@nottingham.ac.uk.
}

\begin{abstract}
Background: The mainstay of treatment for small cell lung cancer (SCLC) involves platinum doublet chemotherapy but the optimal duration, 4 vs. 6 cycles, is not known. Concurrent thoracic radiotherapy followed by prophylactic cranial irradiation (PCI) is recommended for fit individuals with limited stage. However, outside of clinical trials, the efficacy of sequential thoracic radiotherapy and PCI for extensive stage is uncertain.

Methods: This retrospective, observational, cohort study used English national lung cancer data to determine the factors associated with survival for all people diagnosed with SCLC. More precisely, for individuals who received chemotherapy, we examined survival by the chemotherapy duration, thoracic radiotherapy dose and the use of PCI.
\end{abstract}

Results: In total 6,438 people were diagnosed with SCLC. We identified that male sex (OR 0.7; 95\% CI: 0.62-0.80), increasing age $(\mathrm{P}=0.01)$ greater comorbidity $(\mathrm{P} \leq 0.01)$, extensive stage (OR $0.21 ; 95 \%$ CI: 0.19-0.25) and worse performance status (PS2 vs. PS0 adjusted OR 0.38 95\% CI: 0.31-0.48) were associated with reduced 1-year survival. Receipt of chemotherapy augmented survival. We analysed data for 1,761 people who had received chemotherapy. Thoracic radiotherapy ( $\geq 30$ Gy for extensive stage and $\geq 40$ Gy for limited stage) and PCI were independently associated with better survival ( $\mathrm{P} \leq 0.01$ for each), but 6 cycles of chemotherapy instead of 4 was not (limited stage adjusted OR 0.97; 95\% CI: 0.48-1.97) extensive stage adjusted OR 1.34; 95\% CI: 0.81-2.21).

Conclusions: Extending chemotherapy beyond 4 cycles to 6 does not augment survival. Appropriately prescribed thoracic radiotherapy and PCI can prolong survival in both limited and extensive stage SCLC.

Keywords: Lung neoplasms; small cell lung carcinoma; prognosis; cranial irradiation; platinum

Submitted Sep 11, 2020. Accepted for publication Jan 08, 2021.

doi: 10.21037/apm-20-1824

View this article at: http://dx.doi.org/10.21037/apm-20-1824

\section{Introduction}

The international consensus for treatment of small cell lung cancer (SCLC) involves platinum doublet chemotherapy, however, the optimal duration of this (4 or 6 cycles) remains unclear, especially for extensive stage (ED-SCLC) (1-4). Thoracic radiotherapy is an adjunct 
to chemotherapy and evidence suggests that a shorter time to chemo-radiation improves survival, especially for limited stage (LD-SCLC) $(5,6)$. Indeed, for individuals with LD-SCLC and performance status (PS) 0-1, concurrent thoracic radiotherapy is recommended within the first 2 chemotherapy cycles. Sequential consolidative thoracic radiotherapy is recommended for patients that have shown response to chemotherapy who are unfit for concurrent irradiation or have ED-SCLC, but the evidence base outside of clinical trials is sparse. Prophylactic cranial irradiation (PCI) is reserved for people whose cancer has not progressed following first line treatment, however its efficacy in chemotherapy responders with ED-SCLC has been refuted by a recent phase III randomised control trial (7). This has prompted the National Institute for health and Care Excellence (NICE) to downgrade the recommendation from "offer" to "consider" (8). The aforementioned therapies are often confined to specialist cancer hospitals and hence there are likely to be geographical variations in their use (9).

Patients with ED-SCLC are often symptomatic at diagnosis. However, the side effects of treatment and the time spent in hospital may pose a significant burden which can lower the limited quality and quantity of life they have. Therefore, it is important that individuals are offered appropriate treatment with a realistic understanding of the survival gains. Hence, the objectives of this study were to: (I) Quantify the patient, treatment and hospital factors associated with 1-year survival in all people diagnosed with SCLC. (II) Determine whether 6 in comparison to 4 chemotherapy cycles, thoracic radiotherapy and PCI augment the odds of 1-year survival for individuals who receive chemotherapy. We present the following article in accordance with the STROBE reporting checklist (available at http://dx.doi.org/10.21037/apm-20-1824).

\section{Methods}

\section{Study design}

This study was a retrospective analysis of prospectively collected observational cohort data from individuals who were diagnosed with SCLC. The study was conducted in accordance with the declaration of Helsinki (as revised in 2013). We performed a statistical analysis of patient, tumour and treatment factors to assess their impact on 1-year survival in all people diagnosed with SCLC and a subanalysis in those who received chemotherapy. The details of this analysis are outlined below.

\section{Study population}

This was a retrospective cohort study that used English National Lung Cancer Audit (NLCA) data to identify people diagnosed with SCLC from 1st January 2015 to 21st September 2016 based on their histological code. We linked these data with Systemic Anti-Cancer Therapies (SACT), National RadioTherapy DataSet (RTDS) and Hospital Episode Statistics (HES) data. All were prospectively collected via clinical coding or electronic records/ prescriptions. These data are held by Public health England, with whom we had a data-sharing agreement. The data are routinely collected National health service hospital data and consent is assumed unless the patient specifically withdraws this. The data are pseudonymised. Ethical approval was obtained from the NHS Health Research Authority (16/LO/0503).

\section{One-year survival}

Date of death was derived from the Office of National Statistics records. The most recent update to this record was 21st September 2017, therefore each patient had follow up for at least 1-year from their date of diagnosis. 1-year survival was defined as survival greater than or equal to 365 days from the date of diagnosis.

\section{Therapies}

An individual was defined as receiving chemotherapy if there was a record of administration within 6 months after SCLC diagnosis. If no date was present or it was beyond 6 months of diagnosis chemotherapy was classed as not given. The chemotherapy regimens were grouped according to the first chemotherapy drugs that were given except "other". This consisted of drugs given in small quantities e.g., gemcitabine + cisplatin. Chemotherapy regimens that differed to the initial prescription were classed as a second-line treatment and not were analysed. Chemotherapy regimen was classed as "missing" if the administration date was present but drug details were not given. Prior to administering the first chemotherapy cycle the prescriber has to input the planned cycle duration. We used this information for the planned cycle duration. We used the consecutive dates recorded for when a patient received a chemotherapy dose to determine how many cycles of chemotherapy they actually received. 
Radiotherapy was classed as given if an administration date was present after diagnosis. Thoracic radiotherapy was stratified by the maximal dose prescribed. For LSSCLC this was "radical intent" ( $\geq 40$ Gy) and "palliative" ( $<40 \mathrm{~Gy}$ ), whereas for ED-SCLC it was "consolidative" $(\geq 40$ Gy) and "palliative" (<40 Gy). This dose threshold was chosen as it aligned with the Royal College of Radiologists recommendations (10). In addition, we conducted a sensitivity analysis with a dose threshold at $\geq 30$ Gy for radical/consolidative intent. We did not examine whether radiotherapy was fractionated to once or twice daily. Prophylactic Cranial Irradiation (PCI) was defined as radiotherapy given to the skull or with prophylactic intent following chemotherapy at 20 or 25 Gy in 5 or 10 fractions for people with ED-SCLC and 25 Gy in 10 fractions for people with LD-SCLC.

\section{Covariates}

Socioeconomic status was calculated from postcode of residence (Townsend index of deprivation 1-least deprived to 5-most deprived). Performance Status (PS) was classed according to World Health Organisation criteria. A patient's pre-treatment Tumour Node Metastases (TNM) records were used to classify stage into limited and extensive, similar to Veteran Administration Lung Cancer Study Group (VALSG) criteria. ED-SCLC was any $\mathrm{T}$ or $\mathrm{N}$ with $\mathrm{M} 1 \mathrm{a} / \mathrm{b}$ spread (11). Stage was "missing" if TNM was not recorded. Charlson index of co-morbidities was categorised as 0 , $1,2-3$ and $\geq 4$. It was calculated from previous diagnoses (excluding lung cancer) recorded at hospital admissions up to the date of SCLC diagnosis $(12,13)$. Individuals with no prior admissions or comorbidities were assigned a score of 0 . Any variables that had $>50 \%$ missing data were not included in our analysis, e.g., smoking status and forced expiratory volume in 1 second. These were assumed to be missing at random.

\section{Statistical analysis}

All analyses were completed using Stata V15 (Stat Corp, TX USA). We described the whole cohort of people diagnosed from 1st January 2015 to 21 st September 2016 and performed univariate and multivariable logistic regression for the odds of 1-year survival. Our multivariable model for 1-year survival included factors that were $a$ priori or significant on univariate testing $(\mathrm{P} \leq 0.05)$. These factors were age, sex, socioeconomic status, PS, stage, co- morbidities and chemotherapy. This method reduces the effect of selection bias and confounding. We conducted a similar sub-analysis in the 2016 population that received chemotherapy as our radiotherapy data were limited to this time. The multivariable logistic regression model in this sub-analysis included receipt of radiotherapy, PCI and chemotherapy cycles in addition to the previously mentioned factors. We assessed the significance of each variable using the likelihood ratio test.

\section{Results}

\section{Whole SCLC cohort}

There were 6,438 people diagnosed with SCLC whose demographics are summarised in Table 1. Approximately $51.3 \%(\mathrm{n}=3,303)$ were male and the median age was 70 years (IQR 63-76). The majority of individuals had ED-SCLC $[\mathrm{n}=4,264(66.2 \%)]$. We found that $1,860(28.9 \%)$ people survived 1-year. For people with LD-SCLC 1-year survival was $53.8 \%(\mathrm{n}=1,068)$ in contrast to ED-SCLC where this was $17.0 \%(\mathrm{n}=725)$. A total of $1,578(84.8 \%)$ people who survived 1-year received chemotherapy. Chemotherapy was mostly carboplatin + etoposide $(n=1,170)$ or cisplatin + etoposide $(\mathrm{n}=274)$.

\section{One-year survival}

After adjusting for age, sex, socioeconomic status, PS, comorbidities, stage and chemotherapy the multivariable analysis showed significant differences in the odds of 1 -year survival by patient factors (Table 1). Males were less likely to survive compared with females (males adjusted OR 0.70 95\% CI: 0.62-0.80). Similarly, increasing age was associated with poorer survival ( $\mathrm{LR}$ trend $\mathrm{P}=0.01$ ). Individuals with worse PS were less likely to survive 1-year (PS 2 vs. PS 0 adjusted OR 0.38 95\% CI: 0.31-0.48) as were people with more co-morbidities (Charlson index $\geq 4 v s$. 0 adjusted OR $0.6295 \%$ CI: $0.52-0.74)$. Individuals with ED-SCLC were less likely to survive 1 -year in comparison to LD-SCLC (adjusted OR $0.2195 \%$ CI: 0.19-0.25). There was significant variation in 1 -year survival by receipt of chemotherapy. Individuals who did not receive chemotherapy were less likely to survive than those who were given carboplatin + etoposide (adjusted OR 0.28 95\% CI: 0.24-0.33). In contrast, people receiving cisplatin + etoposide were more likely to survive ( $v s$. carboplatin + etoposide adjusted OR 1.57 95\% CI: 1.23-1.99) however, 
Table 1 Features of patients diagnosed with SCLC and people that survived 1-year from diagnosis with odds ratios for 1-year survival

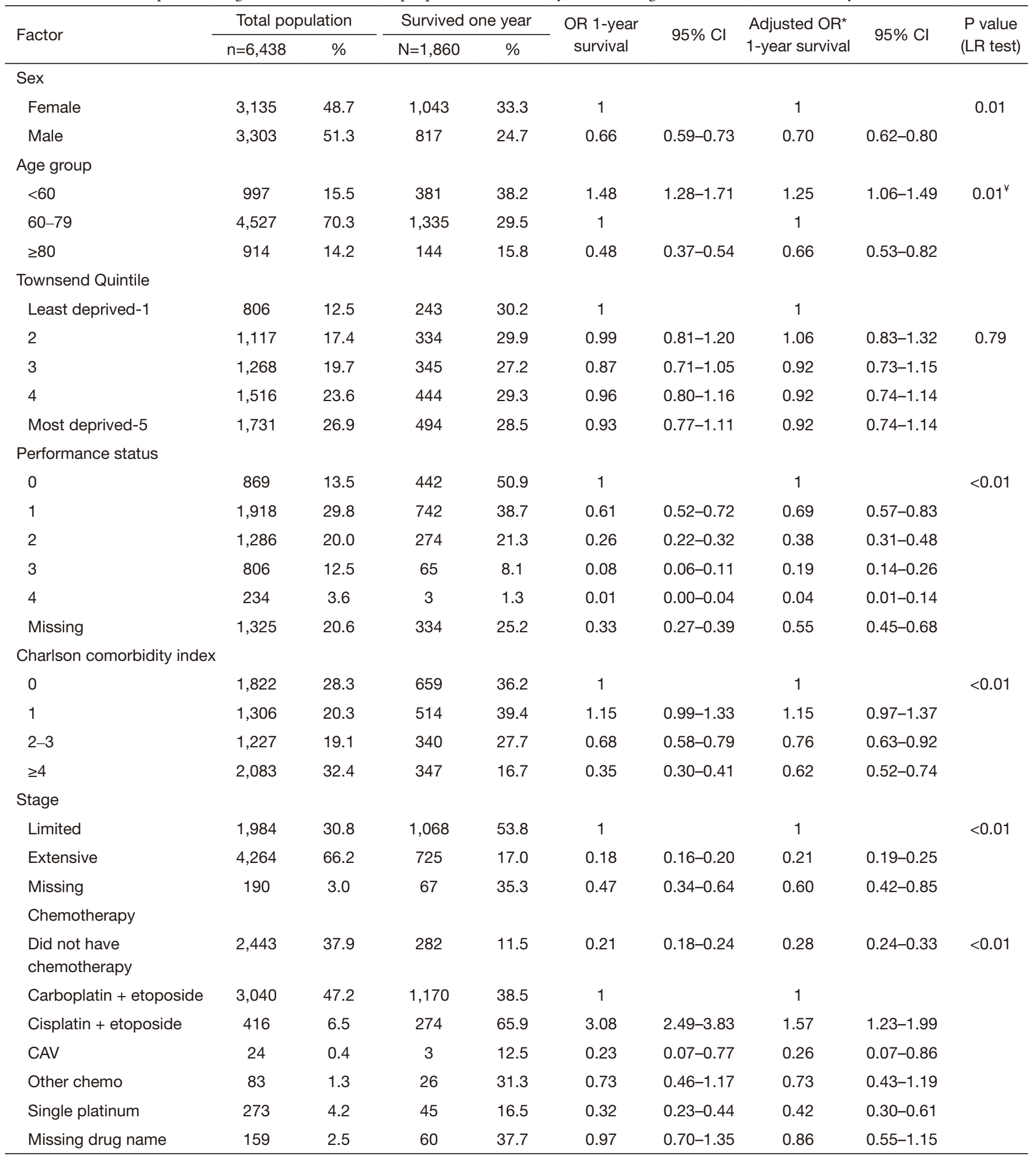

LR, likelihood ratio test. *Adjusted for all other variables in table; ${ }^{*}$, LR test trend. 
PS, comorbidities and stage were confounders to this. Receipt of a single platinum drug conferred poorer survival (vs. carboplatin + etoposide adjusted OR 0.42 95\% CI: $0.30-0.61)$. Socioeconomic status was not associated with survival $(\mathrm{P}=0.79)$.

\section{Survival following receipt of chemotherapy}

We identified 1,761 individuals who were diagnosed in 2016 and received chemotherapy. Of these, 695 (39.5\%) survived 1 -year. Survival varied considerably by stage, hence our results are presented by LD-SCLC and EDSCLC separately (combined stage survival can be found in Table S1).

\section{Limited stage}

The 1-year survival for people with LD-SCLC who received chemotherapy was $60.7 \%(\mathrm{n}=381)$. The following results are shown in Table 2. After adjustment for patient, tumour, chemotherapy and radiotherapy 1-year survival was associated with PS (PS 3-4 vs. PS 0 adjusted OR 0.32 95\% CI: 0.13-0.77). Individuals who were given cisplatin + etoposide were more likely to survive 1 -year compared with carboplatin + etoposide (adjusted OR 2.09 95\% CI: 1.17-3.74), but PS was a confounding factor. Receipt of radical radiotherapy was associated with better survival in comparison to not receiving radiotherapy (radical adjusted OR 3.32 95\% CI: 2.07-5.31). This association remained, although less pronounced, when the radical threshold total radiotherapy dose was set to $30 \mathrm{~Gy}$ (vs. nil radiotherapy adjusted OR 2.83 95\% CI: 1.84-4.34, Table S2). PCI augmented the odds of 1-year survival (adjusted OR 2.42 95\% CI: 1.33-4.39). There was no independent association between survival and age $(\mathrm{P}=0.59)$, sex $(\mathrm{P}=0.07)$, comorbidity score $(\mathrm{P}=0.32)$ and the number of chemotherapy cycles administered $(\mathrm{P}=0.53)$. We conducted a sub analysis of the characteristics of the patients who received $4 v s .6$ chemotherapy cycles and have included these results in Table S3. Both groups were evenly matched.

\section{Extensive stage}

Fewer people survived 1-year with ED-SCLC than LDSCLC $(26.2 \% \mathrm{n}=286)$. The associated patient factors differed to LD-SCLC (shown in Table 3), in particular sex (male vs. female adjusted OR 0.53 95\% CI: 0.39-0.73) and co-morbidity (co-morbidity score $\geq 4 v s$. 0 adjusted OR $0.6495 \%$ CI: 0.43-0.94). PS was a significant prognostic factor $(\mathrm{P} \leq 0.01)$ whereas socioeconomic status $(\mathrm{P}=0.16)$ and age $(P$ trend $=0.30)$ were not. The odds of survival differed by the chemotherapy cycles received. Individuals receiving less than the planned amount of cycles (mean 3 cycles received) were less likely to survive 1-year (vs. 4 cycles adjusted OR 0.37 95\% CI: 0.23-0.61). Similarly, people that received a planned amount of chemotherapy that was fewer than 4 cycles in length (mean 2 cycles) were less likely to survive (vs. 4 cycles adjusted OR $0.2795 \%$ CI: 0.09-0.76). Six chemotherapy cycles did not augment survival in comparison to 4 (6 vs. 4 adjusted OR 1.34 95\% CI: 0.81-2.21). We performed a sub analysis of both 4 and 6 chemotherapy cycle groups and these data can be seen in Table S4. On the whole the groups were evenly balanced with the exception of PS (6 cycles PS0 21\% vs. 4 cycles PS0 11\%).

Receipt of PCI was associated with improved 1-year survival (received PCI adjusted OR 2.04 95\% CI: 1.42 2.93). However, PCI was mostly offered to individuals who were younger [median age for PCI 64 years (IQR 59-70) vs. 69 years $(62-75)$ no PCI] and had better PS (received PCI PS0 $23 \% v s$. no PCI PS0 16\%). These results can be found in Table S5. The median radiotherapy dose prescribed in ED-SCLC was 30Gy. A total radiotherapy dose of $\geq 40$ Gy threshold both consolidative and palliative radiotherapy favoured survival but lacked statistical significance (consolidative $\geq 40$ Gy $v$ s. nil adjusted OR 1.88 95\% CI: $0.91-3.87$ and palliative $v s$. no radiotherapy adjusted OR $1.3795 \%$ CI: 0.99-1.90). Reducing the threshold to $\geq 30$ Gy resulted in consolidative radiotherapy being associated with improved survival and reduced the odds of survival with palliative radiotherapy (consolidative $\geq 30$ Gy $v$ s. nil adjusted OR 1.78 95\% CI: 1.22-2.59, Table 4). In general, patients who received palliative radiotherapy $<30$ Gy were older [median age 68 years (IQR 62-74)] in comparison to those who received consolidative radiotherapy $\geq 30$ Gy [65years $\geq 30$ Gy (IQR 60-72)]. In addition, there was a greater proportion of severe comorbidity and males in the group who received palliative radiotherapy ( $<30 \mathrm{~Gy}$ ) (Charlson score $\geq 4.42 \%$ palliative $v s .28 \%$ consolidative). Table S6 is a table showing the patient demographics.

The chemotherapy regimen was not independently associated with survival $(\mathrm{P}=0.12)$. However, individuals that received single platinum therapy were less likely to survive 1-year (vs. carboplatin + etoposide adjusted OR 0.36 95\% 
Table 2 Features of patients with limited stage who received chemotherapy and survived 1 year with odds ratios for 1 year survival

\begin{tabular}{|c|c|c|c|c|c|c|c|}
\hline Factor & $\begin{array}{c}\text { Number surviving } \\
1 \text { year }(n=381 \text { from } \\
628)\end{array}$ & $\begin{array}{c}\% \text { who survived } \\
1 \text { year from all } \\
\text { who received } \\
\text { chemotherapy }\end{array}$ & $\begin{array}{l}\text { OR 1-year } \\
\text { survival }\end{array}$ & $95 \% \mathrm{Cl}$ & $\begin{array}{l}{ }^{*} \text { Adjusted OR } \\
1 \text {-year survival }\end{array}$ & $95 \% \mathrm{Cl}$ & $\begin{array}{l}\mathrm{P} \text { value } \\
\text { (LR test) }\end{array}$ \\
\hline \multicolumn{8}{|l|}{ Sex } \\
\hline Female & 220 & 65.1 & 1 & & 1 & & 0.07 \\
\hline \multicolumn{8}{|l|}{ Age group } \\
\hline$<60$ & 78 & 73.6 & 1.92 & $1.20-3.08$ & 1.20 & $0.69-2.09$ & $0.59^{\neq}$ \\
\hline $60-79$ & 271 & 59.2 & 1 & & 1 & & \\
\hline$\geq 80$ & 32 & 50.0 & 0.69 & $0.41-1.17$ & 0.86 & $0.47-1.57$ & \\
\hline 2 & 53 & 52.5 & 0.57 & $0.32-1.04$ & 0.46 & $0.23-0.92$ & \\
\hline 3 & 74 & 61.7 & 0.83 & $0.47-1.49$ & 1.03 & $0.53-2.00$ & \\
\hline 4 & 98 & 58.3 & 0.73 & $0.42-1.25$ & 0.73 & $0.39-1.36$ & \\
\hline Most deprived-5 & 100 & 64.9 & 0.96 & $0.55-1.67$ & 1.10 & $0.57-2.10$ & \\
\hline \multicolumn{8}{|l|}{ Performance status } \\
\hline 0 & 110 & 69.2 & 1 & & 1 & & 0.02 \\
\hline 1 & 171 & 65.8 & 0.86 & $0.56-1.31$ & 1.04 & $0.64-1.69$ & \\
\hline 2 & 63 & 48.8 & 0.43 & $0.26-0.69$ & 0.63 & $0.36-1.11$ & \\
\hline $2-3$ & 86 & 52.8 & 0.53 & $0.35-0.82$ & 0.75 & $0.45-1.24$ & \\
\hline$\geq 4$ & 52 & 50.5 & 0.49 & $0.30-0.79$ & 0.83 & $0.47-1.47$ & \\
\hline \multicolumn{8}{|l|}{ Chemotherapy } \\
\hline Carboplatin+ etoposide & 254 & 57.0 & 1 & & 1 & & 0.01 \\
\hline Cisplatin + etoposide & 107 & 82.3 & 3.52 & $2.16-5.73$ & 2.09 & $1.17-3.74$ & \\
\hline Other & 8 & 72.7 & 2.02 & $0.53-7.70$ & 3.64 & $0.84-15.66$ & \\
\hline Single platinum & 9 & 29.0 & 0.31 & $0.14-0.67$ & 0.55 & $0.23-1.34$ & \\
\hline Missing & 3 & 30.0 & 0.32 & $0.08-1.27$ & 0.43 & $0.08-2.27$ & \\
\hline
\end{tabular}

Table 2 (continued) 
Table 2 (continued)

\begin{tabular}{|c|c|c|c|c|c|c|c|}
\hline Factor & $\begin{array}{l}\text { Number surviving } \\
1 \text { year }(n=381 \text { from } \\
628)\end{array}$ & $\begin{array}{l}\% \text { who survived } \\
1 \text { year from all } \\
\text { who received } \\
\text { chemotherapy }\end{array}$ & $\begin{array}{l}\text { OR 1-year } \\
\text { survival }\end{array}$ & $95 \% \mathrm{Cl}$ & $\begin{array}{l}{ }^{*} \text { Adjusted OR } \\
\text { 1-year survival }\end{array}$ & $95 \% \mathrm{Cl}$ & $\begin{array}{l}\text { P value } \\
\text { (LR test) }\end{array}$ \\
\hline \multicolumn{8}{|l|}{ Chemotherapy cycles received } \\
\hline $\begin{array}{l}\text { More than planned (mean } \\
4 \text { cycles) }\end{array}$ & 10 & 71.4 & 0.75 & $0.21-2.64$ & 0.80 & $0.19-3.34$ & 0.53 \\
\hline 4 planned and received & 70 & 76.9 & 1 & & 1 & & \\
\hline 6 planned and received & 80 & 67.8 & 0.63 & $0.34-1.18$ & 0.97 & $0.48-1.97$ & \\
\hline $\begin{array}{l}\text { Received planned amount } \\
\text { that was fewer than } 4 \\
\text { cycles (mean } 2 \text { cycles) }\end{array}$ & 18 & 52.9 & 0.34 & $0.15-0.78$ & 0.70 & $0.24-2.04$ & \\
\hline \multicolumn{8}{|l|}{ Received radiotherapy } \\
\hline $\begin{array}{l}\text { Did not receive } \\
\text { radiotherapy }\end{array}$ & 119 & 44.2 & 1 & & 1 & & $<0.01$ \\
\hline Radical ( $\geq 40$ Gy) & 197 & 81.4 & 5.52 & $3.69-8.26$ & 3.32 & $2.07-5.31$ & \\
\hline Palliative (<40 Gy) & 65 & 55.6 & 1.58 & $1.02-2.44$ & 1.53 & $0.94-2.49$ & \\
\hline \multicolumn{8}{|l|}{ Received PCl } \\
\hline No & 261 & 53.4 & 1 & & 1 & & $<0.01$ \\
\hline
\end{tabular}

${ }^{*}$, LR test for trend. *Adjusted OR for all other factors in table.

Table 3 Features of patients with extensive stage who received chemotherapy and survived 1 year with odds ratios for 1 year survival

\begin{tabular}{|c|c|c|c|c|c|c|c|}
\hline Factor & $\begin{array}{c}\text { Number } \\
\text { surviving } 1 \text { year } \\
(\mathrm{n}=286 \text { from } \\
1,091)\end{array}$ & $\begin{array}{l}\% \text { who survived } \\
1 \text { year from all } \\
\text { who received } \\
\text { chemotherapy }\end{array}$ & $\begin{array}{l}\text { OR 1-year } \\
\text { survival }\end{array}$ & $95 \% \mathrm{Cl}$ & $\begin{array}{l}{ }^{*} \text { Adjusted OR } \\
1 \text {-year survival }\end{array}$ & $95 \% \mathrm{Cl}$ & $\begin{array}{l}\mathrm{P} \text { value } \\
\text { (LR test) }\end{array}$ \\
\hline \multicolumn{8}{|l|}{ Sex } \\
\hline Female & 166 & 31.4 & 1 & & 1 & & $<0.01$ \\
\hline$<60$ & 64 & 29.6 & 0.88 & $0.63-1.23$ & 1.10 & $0.75-1.62$ & $0.30^{¥}$ \\
\hline $60-79$ & 210 & 27.1 & 1 & & 1 & & \\
\hline$\geq 80$ & 12 & 12.1 & 0.33 & $0.17-0.64$ & 0.59 & $0.28-1.26$ & \\
\hline Townsend quintile & & & & & & & \\
\hline
\end{tabular}

Table 3 (continued) 
Table 3 (continued)

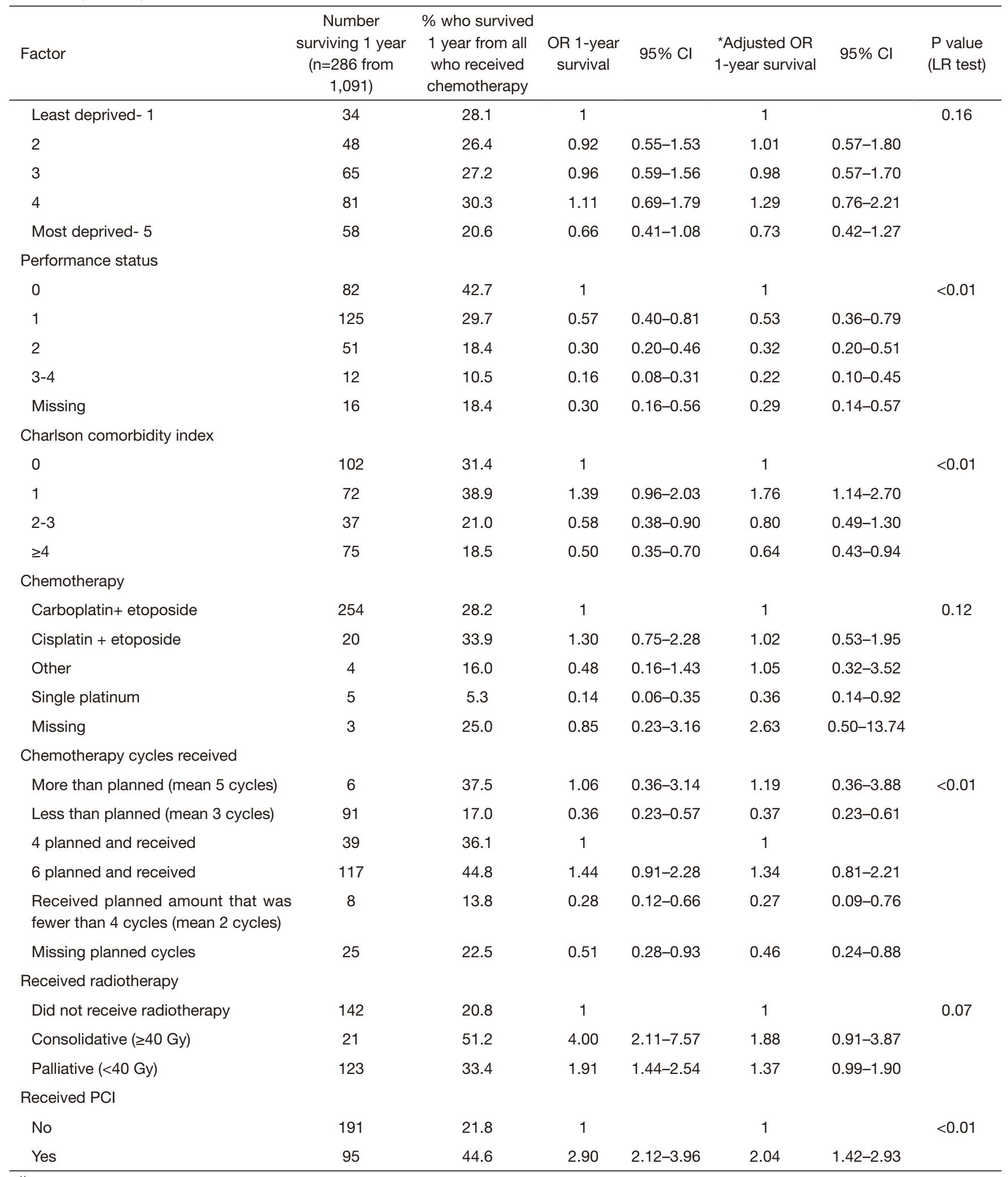

${ }^{*}$, LR test for trend; *Adjusted OR for all other factors in table. 
Table 4 Sensitivity analysis of 1-year survival with different radiotherapy thresholds for extensive stage SCLC

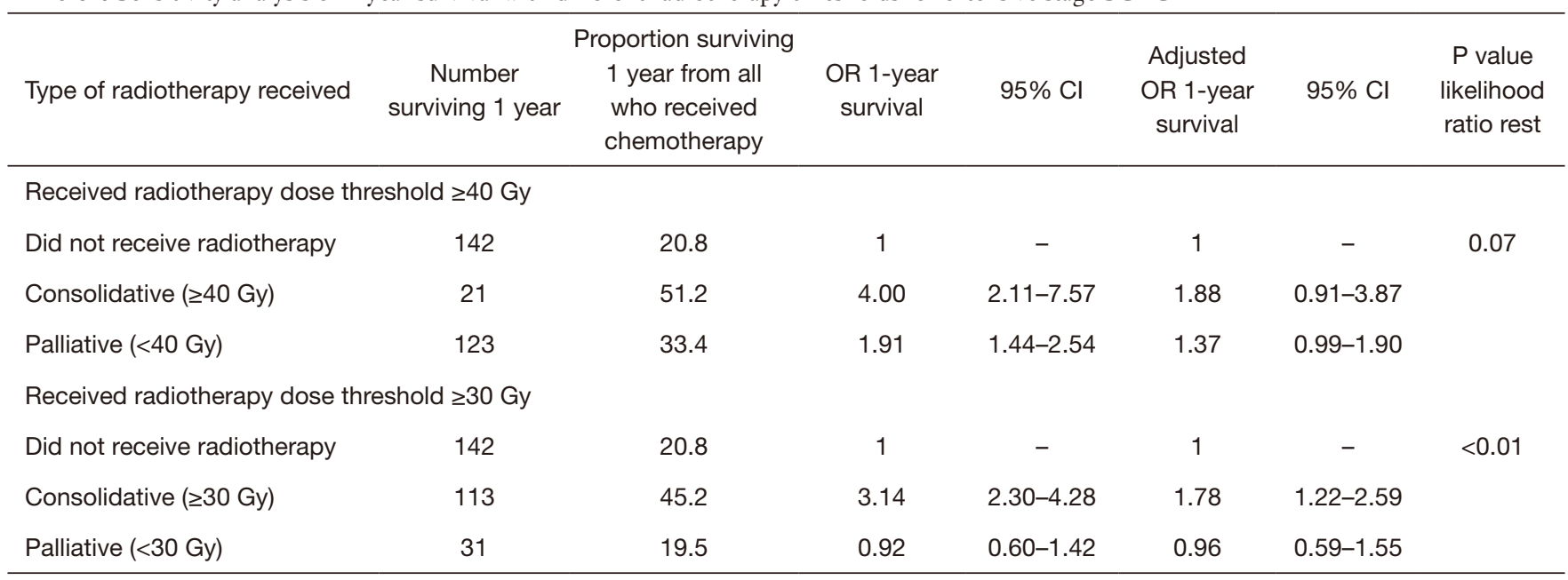

Odds ratios are adjusted for sex, age, social deprivation, PS, comorbidity, receipt of $\mathrm{PCl}$, chemotherapy regimen and cycles.

CI: 0.14-0.92).

\section{Discussion}

\section{Main findings}

We have shown that in all persons diagnosed with SCLC sex, age, PS, co-morbidity, stage and receipt of chemotherapy are independently associated with 1-year survival. For those individuals who go on to receive chemotherapy the majority of these factors, with the addition of radiotherapy and PCI, but not age, were also associated with 1-year survival. Continuing chemotherapy to 6 cycles did not increase the odds of 1-year survival in comparison to 4.

\section{Strengths}

These results provide an up-to date "real world" benchmark of survival for SCLC. 1-year survival is an important landmark that is sensitive to treatment effects in this aggressive cancer. Observational studies on this topic are important to confirm the impact of treatment recommendations derived from clinical trials. The complex linkage of national data used in our study provides a comprehensive picture of the treatments given for SCLC and importantly their survival impact to better inform treatment decisions for clinicians and patients. These data have enabled us to study a large population, which in turn, increases the reliability of our results as smaller studies are more susceptible to bias, especially due to selection of healthier patients. Our data are likely to be reliable because there are quality assurance standards applied to the collection. Outlier hospitals that fall below 2-3 standard deviations from the national audit standard are investigated and their data submissions are reviewed.

\section{Limitations}

Our findings may be subject to bias, but these are likely to be lower in magnitude than for clinical trials. Some variables are prone to immortal time bias, however, many of the therapies for SCLC are given within days of diagnosis. Hence, the few days survival advantage treated groups have is too small a proportion of the 1 -year survival to significantly bias our results. Similarly, individuals who receive treatment may inherently be healthier and fitter in comparison to those that do not receive treatment and therefore are more likely to survive. However, by adjusting for PS and comorbidity this selection bias is lessened and in the case of chemotherapy cycles these biases would tend to favour survival with 6 cycles over 4 , which was not demonstrated in this research. The planned chemotherapy cycles is an estimated amount and in some patients this value may not actually reflect the intended duration as those that are less fit are sometimes given chemotherapy on a cycle-by-cycle basis. Lastly, our data did not contain the time to disease progression. Progression free survival is considered an important metric in the evaluation of 
treatment efficacy but is not the gold standard. Similarly, from a patient perspective overall survival may be a more important metric. Our method of calculating Charlson comorbidity index may overestimate the number of people with no comorbidity. These comorbidity data are only captured when a patient is admitted to hospital and therefore those who are managed as an outpatient may have no comorbidity data recorded. However, over 2 thirds of people in our dataset had a Charlson score of $>0$.

\section{Comparisons with other research}

\section{One-year survival}

After chemotherapy 1 year survival in our study was approximately $26 \%$ for ED-SCLC and $60 \%$ LD-SCLC. In comparison a systematic review that examined oneyear survival from mostly clinical trial research estimated 1 year survival to be approximately $73 \%$ in LD-SCLC and $38 \%$ in ED-SCLC (14). Better survival in clinical trials can be explained by selection bias. Indeed most clinical trials included patients with PS $0-1$ and excluded patients with brain metastases whereas our study cohort is unselected in this regard.

\section{Patient factors}

The associated survival factors identified in our study have been identified previously for all people diagnosed with SCLC. Females were more likely to survive 1 year than males. This finding may relate to greater cardiovascular comorbidity in men or delayed presentation. Other factors which might be part of this finding are differences in drug metabolism between the sexes, whereby females have higher circulating concentrations of cytotoxic drug metabolites. This has been hypothesised in non-small cell lung cancer (15). Similarly, it has been shown that females have decreased DNA repair capacity and have higher DNA adducts which is relevant to platinum agents as these work by inhibiting DNA repair causing further DNA adducts triggering cellular apoptosis(16-19) In addition, hormonal factors, such as estrogen, may also influence SCLC survival. Indeed, when estrogen beta receptors have been identified on SCLC cells from males this has been associated with better survival (20).

Age ( $<70$ years) has been shown to confer better long term survival in clinical trials as well as real world settings $(21,22)$. Indeed, for all patients diagnosed with SCLC those who were $>79$ years old were less likely to survive. This is likely a reflection of selection bias due to increased comorbidity and treatment nihilism in this group of patients i.e., patients are less likely to want treatment (23). This hypothesis is supported by our sub analysis of patients who received chemotherapy where we found that age was not a prognostic factor as comorbidity and PS are the main factors that determine whether chemotherapy can be administered (24) Survival was not considerably different for people with LD-SCLC who were PS 0 and 2. This finding is inconsistent with other research and is likely a result of small patient numbers not giving rise to statistical significance. Indeed overall, we found that PS was an independently associated factor with 1-year survival. This finding, in addition to stage, is consistent with other research and both are used in the Manchester prognostic score to estimate 2-year survival (25). Rich et al. demonstrated that a worse Charlson Index was associated with poorer survival in all stages of SCLC (9).

\section{Chemotherapy}

Contrary to our observation of better survival with cisplatin + etoposide in LD-SCLC, a meta-analysis of individual patient data has shown no difference between carboplatin $v s$. cisplatin regimens (26). The difference in our results may relate to residual selection bias in our cohort. Indeed, PS was a strong confounder to receiving chemotherapy, suggesting cisplatin was reserved for fitter individuals and people receiving concurrent chemo-radiotherapy. Similarly, single agent platinum was mostly given to people who had worse PS or died before receiving etoposide. In clinical practice clinicians may select carboplatin over cisplatin when prognosis is short due to a favourable side effect profile and convenience of administration.

\section{PCI}

There is strong clinical trial evidence to support PCI use in LD-SCLC. A systematic review which included mostly LD-SCLC patients from 7 clinical trials found that PCI improved survival for people who were in complete remission following chemo-radiotherapy for SCLC (27). The evidence for the benefit of PCI in ED-SCLC is less clear. The European Organisation for Research and Treatment of Cancer (EORTC) showed, in 2007, that PCI augmented survival for individuals with ED-SCLC who had responded to chemotherapy (28). However, this study did not report response to chemotherapy or screen for asymptomatic brain metastases in all participants. More 
recently, with the pitfalls of the EORTC study addressed, a phase III randomized controlled trial found that PCI did not augment survival in a cohort consisting mostly of partial chemotherapy responders with ED-SCLC (7). Importantly, in our study, patients who received PCI were younger and had better PS than those who did not. This suggests that in order to achieve this survival benefit careful treatment selection is needed. We were unable to ascertain the response to chemotherapy before PCI administration. However, one can assume that PCI was given to individuals who had responded to chemotherapy, in accordance with treatment recommendations $(1,2)$.

\section{Radiotherapy}

Radiotherapy doses $\geq 40$ Gy augmented the odds of 1-year survival but lacked statistical significance in ED-SCLC. When reduced to $\geq 30$ Gy these odds decreased for LDSCLC and became statistically significant for ED-SCLC. This is the resultant effect of 30 Gy doses being used for palliative as well as consolidative (life prolonging) treatment, in addition it is the median dose prescribed for ED-SCLC. The lowest recommended dose by the Royal College of Radiologists to treat LD-SCLC is 40 Gy whereas, for EDSCLC, 30 Gy can be used as consolidation therapy in chemotherapy responders (where the goal is to prolong survival) or as palliation of persistent thoracic symptoms following chemotherapy (10).

In LD-SCLC the survival benefits of early thoracic radiotherapy within the first 2 cycles of chemotherapy were established using a schedule of 40 Gy in 15 fractions (29). Other studies have also given $\geq 40$ Gy but have investigated the delivery of radiotherapy i.e., once $v s$. twice daily. Turrisi et al. found that a total dose of 45 Gy given twice daily was superior to once daily (30). This finding was validated by the CONVERT trial which demonstrated that a total dose of 66 Gy given as 2 Gy in once daily fractions was no better, in terms of survival and toxicity, than a total dose of 45 Gy given in twice daily fractions (31). Nevertheless, both these regimens would have been captured in our radical radiotherapy group.

For ED-SCLC the addition of thoracic radiotherapy in chemotherapy responders has been associated with improved survival before (32). A meta-analysis of two randomized controlled trials that gave $30 \mathrm{~Gy}$ in 10 fractions and 54 Gy in 36 fractions found that thoracic radiotherapy augmented survival in chemotherapy responders when compared no radiotherapy (HR 0.81 95\% CI: 0.69-0.96).
The typical radiotherapy dose given in the palliative dosing group was $8 \mathrm{~Gy}$ in 1 fraction. We found this had no benefit to survival in comparison to not receiving radiotherapy. This finding is congruous with the main aim of palliative radiotherapy being to reduce symptoms and not prolong survival.

\section{Cycles of chemotherapy}

There was no difference between 1-year survival of 4 and 6 cycles of chemotherapy in our study and the supporting evidence in this area is limited. Powell et al. found a reduction in the risk of death when more chemotherapy cycles were given but was unable to directly compare 4 with 6 (33). To our knowledge only one study has compared both and found no difference in survival for LD-SCLC patients and a trend to improved survival with 6 cycles for EDSCLC, but this lacked statistical significance $(\mathrm{P}=0.09)$ (4) In our study, the poorer survival associated with receiving less than the planned amount of chemotherapy in ED-SCLC is a reflection of underlying treatment selection bias that we were unable to adjust for. This would include factors such as: disease progression (treatment failure), complications and side effects. These factors were not recorded in the data we analysed.

\section{Relevance}

Our findings relate to clinical practice and add to the evidence base for treatment recommendations. We have shown that thoracic radiotherapy (above 40 Gy in LDSCLC and 30 Gy in ED-SCLC) and PCI are associated with improved 1-year survival and that 6 cycles of chemotherapy is no better than 4 . This may serve to ensure that the treatment emphasis is placed on delivering more effective radiotherapy as opposed to extending chemotherapy beyond 4 cycles.

\section{Conclusions}

This research adds further evidence to factors associated with long-term survival in SCLC. Receiving chemotherapy is one of the strongest predictors of survival. Balancing the survival benefits of chemotherapy with the toxicities is important if quality as well as quantity of life is to be preserved. We have shown that this may be supported by giving 4 cycles of chemotherapy rather than 6 , as there is no survival advantage from the latter. Appropriate administration of radiotherapy and PCI should be 
encouraged as they provide a survival benefit. In the future, advances in SCLC survival may come from adding novel therapies to four cycles of optimally delivered chemo and radiotherapy and prospective collection of national lung cancer data, like that used in this analysis, will be a key resource in measuring the success (34).

\section{Acknowledgments}

Funding: This research was funded by the Roy Castle lung cancer foundation (grant number 201514 Hubbard) and the University of Nottingham John Turland charitable fund. Neither were involved in the design, analysis or interpretation of results.

\section{Footnote}

Reporting Checklist: The authors have completed the STROBE reporting checklist. Available at http://dx.doi. org/10.21037/apm-20-1824

Data Sharing Statement: Available at http://dx.doi. org/10.21037/apm-20-1824

Conflicts of Interest: All authors have completed the ICMJE uniform disclosure form (available at http://dx.doi. org/10.21037/apm-20-1824). Dr. Jones reports grants from Roy castle lung cancer foundation, from University of Nottingham John Turland fund, during the conduct of the study. Dr. Khakwani reports at the time of analysis and editing of the manuscript he was employed by the University of Nottingham. Dr. Khakwani now works for British American tobacco, conducting epidemiological research for e-cigarettes and has not contributed to any revisions of the manuscript since taking up this position. Prof. McKeever reports grants from Roy castle lung cancer foundation, grants from University of Nottingham John Turland fund, during the conduct of the study. Prof. Hubbard reports grants from Roy castle lung cancer foundation, grants from University of Nottingham John Turland fund, during the conduct of the study. Prof. Baldwin reports grants from Roy castle lung cancer foundation, grants from University of Nottingham John Turland fund, during the conduct of the study; and Received honoraria from Astra Zeneca, Roche, Bristol Myer Squibs and Merck Sharp and Dome for work on CT screening, COVID and early diagnosis. The authors have no other conflicts of interest to declare.
Ethical Statement: The authors are accountable for all aspects of the work in ensuring that questions related to the accuracy or integrity of any part of the work are appropriately investigated and resolved. The study was conducted in accordance with the Declaration of Helsinki (as revised in 2013). The data are routinely collected National health service hospital data and consent is assumed unless the patient specifically withdraws this. Ethical approval was obtained from the NHS Health Research Authority, London- Camden and King's cross research ethics committee (Reference 16/LO/0503).

Open Access Statement: This is an Open Access article distributed in accordance with the Creative Commons Attribution-NonCommercial-NoDerivs 4.0 International License (CC BY-NC-ND 4.0), which permits the noncommercial replication and distribution of the article with the strict proviso that no changes or edits are made and the original work is properly cited (including links to both the formal publication through the relevant DOI and the license). See: https://creativecommons.org/licenses/by-nc-nd/4.0/.

\section{References}

1. Jett JR, Schild SE, Kesler KA, et al. Treatment of small cell lung cancer: Diagnosis and management of lung cancer, 3rd ed: American College of Chest Physicians evidencebased clinical practice guidelines. Chest 2013;143:e400Se419S.

2. Früh M, De Ruysscher D, Popat S, et al. Small-cell lung cancer (SCLC): ESMO Clinical Practice Guidelines for diagnosis, treatment and follow-up†. Ann Oncol 2013;24:vi99-vi105.

3. NICE. Lung cancer: diagnosis and management CG121. 2011.

4. Veslemes M, Polyzos A, Latsi P, et al. Optimal duration of chemotherapy in small cell lung cancer: a randomized study of 4 versus 6 cycles of cisplatin-etoposide. J Chemother 1998;10:136-40.

5. De Ruysscher D, Lueza B, Le Péchoux C, et al. Impact of thoracic radiotherapy timing in limited-stage small-cell lung cancer: usefulness of the individual patient data metaanalysist. Ann Oncol 2016;27:1818-28.

6. De Ruysscher D, Pijls-Johannesma M, Bentzen SM, et al. Time between the first day of chemotherapy and the last day of chest radiation is the most important predictor of survival in limited-disease small-cell lung cancer. J Clin 
Oncol 2006;24:1057-63.

7. Takahashi T, Yamanaka T, Seto T, et al. Prophylactic cranial irradiation versus observation in patients with extensive-disease small-cell lung cancer: a multicentre, randomised, open-label, phase 3 trial. Lancet Oncol 2017;18:663-71.

8. NICE. Treating small cell lung cancer. 2020.

9. Rich AL, Tata LJ, Free CM, et al. How do patient and hospital features influence outcomes in small-cell lung cancer in England? Br J Cancer 2011;105:746-52.

10. Radiologists Rco. Radiotherapy dose fractionation, second edition. 2016.

11. Micke P, Faldum A, Metz T, et al. Staging small cell lung cancer: Veterans Administration Lung Study Group versus International Association for the Study of Lung Cancerwhat limits limited disease? Lung Cancer 2002;37:271-6.

12. Khakwani A, Rich AL, Tata LJ, et al. Small-cell lung cancer in England: Trends in survival and chemotherapy using the national lung cancer audit. PLoS One 2014;9:e89426.

13. Charlson ME, Pompei P, Ales KL, et al. A new method of classifying prognostic comorbidity in longitudinal studies: development and validation. J Chronic Dis 1987;40:373-83.

14. Jones GS, Elimian K, Baldwin DR, et al. A systematic review of survival following anti-cancer treatment for small cell lung cancer. Lung Cancer 2020;141:44-55.

15. Wakelee HA, Wang W, Schiller JH, et al. Survival Differences by Sex for Patients with Advanced Non-small Cell Lung Cancer on Eastern Cooperative Oncology Group Trial 1594. J Thorac Oncol 2006;1:441-6.

16. Spitz MR, Wei Q, Dong Q, et al. Genetic susceptibility to lung cancer: the role of DNA damage and repair. Cancer Epidemiol Biomarkers Prev 2003;12:689-98.

17. Mollerup S, Ryberg D, Hewer A, et al. Sex differences in lung CYP1A1 expression and DNA adduct levels among lung cancer patients. Cancer Res 1999;59:3317-20.

18. Wei Q, Cheng L, Amos CI, et al. Repair of Tobacco Carcinogen-Induced DNA Adducts and Lung Cancer Risk: a Molecular Epidemiologic Study. J Natl Cancer Inst 2000;92:1764-72.

19. Siddik $\mathrm{ZH}$. Cisplatin: mode of cytotoxic action and molecular basis of resistance. Oncogene 2003;22:7265-79.

20. Curioni-Fontecedro A, Soldini D, Seifert B, et al. A Comprehensive Analysis of Markers for Neuroendocrine Tumors of the Lungs Demonstrates Estrogen Receptor Beta to be a Prognostic Markers in SCLC Male Patients. J Cytol Histol 2014;5:268.
21. Osterlind K, Andersen PK. Prognostic factors in small cell lung cancer: multivariate model based on 778 patients treated with chemotherapy with or without irradiation. Cancer Res 1986;46:4189-94.

22. Gaspar LE, McNamara EJ, Gay EG, et al. Small-cell lung cancer: prognostic factors and changing treatment over 15 years. Clin Lung Cancer 2012;13:115-22.

23. Langer CJ. Elderly patients with lung cancer: biases and evidence. Curr Treat Options Oncol 2002;3:85-102.

24. Jones GS, McKeever TM, Hubbard RB, et al. Factors influencing treatment selection and 30-day mortality after chemotherapy for people with small-cell lung cancer: An analysis of national audit data. Eur J Cancer 2018;103:176-83.

25. Cerny T, Blair V, Anderson H, et al. Pretreatment prognostic factors and scoring system in 407 small-cell lung cancer patients. Int J Cancer 1987;39:146-9.

26. Rossi A, Maio MD, Chiodini P, et al. Carboplatin- or Cisplatin-Based Chemotherapy in First-Line Treatment of Small-Cell Lung Cancer: The COCIS Meta-Analysis of Individual Patient Data. J Clin Oncol 2012;30:1692-8.

27. Aupérin A, Arriagada R, Pignon JP, et al. Prophylactic Cranial Irradiation for Patients with Small-Cell Lung Cancer in Complete Remission. N Engl J Med 1999;341:476-84.

28. Slotman B, Faivre-Finn C, Kramer G, et al. Prophylactic Cranial Irradiation in Extensive Small-Cell Lung Cancer. N Engl J Med 2007;357:664-72.

29. Murray N, Coy P, Pater JL, et al. Importance of timing for thoracic irradiation in the combined modality treatment of limited-stage small-cell lung cancer. The National Cancer Institute of Canada Clinical Trials Group. J Clin Oncol 1993;11:336-44.

30. Turrisi AT 3rd, Kim K, Blum R, et al. Twice-daily compared with once-daily thoracic radiotherapy in limited small-cell lung cancer treated concurrently with cisplatin and etoposide. N Engl J Med 1999;340:265-71.

31. Faivre-Finn C, Snee M, Ashcroft L, et al. Concurrent once-daily versus twice-daily chemoradiotherapy in patients with limited-stage small-cell lung cancer (CONVERT): an open-label, phase 3, randomised, superiority trial. Lancet Oncol 2017;18:1116-25.

32. Palma DA, Warner A, Louie AV, et al. Thoracic Radiotherapy for Extensive Stage Small-Cell Lung Cancer: A Meta-Analysis. Clin Lung Cancer 2016;17:239-44.

33. Powell HA, Tata LJ, Baldwin DR, et al. Treatment decisions and survival for people with small-cell lung cancer. Br J Cancer 2014;110:908-15. 
34. Komarnitsky PB, Lee HJ, Shah M, et al. A phase III study of rovalpituzumab tesirine maintenance therapy following first-line platinum-based chemotherapy in patients with

Cite this article as: Jones GS, Khakwani A, Pascoe A, Foweraker K, McKeever TM, Hubbard RB, Baldwin DR. Factors associated with survival in small cell lung cancer: an analysis of real-world national audit, chemotherapy and radiotherapy data. Ann Palliat Med 2021;10(4):4055-4068. doi: 10.21037/apm-20-1824 extensive disease small cell lung cancer (ED SCLC). J Clin Oncol 2017;35:TPS8583. 
Table S1 Features of patients who received chemotherapy and survived 1 year with odds ratios for 1 year survival in all stages

\begin{tabular}{|c|c|c|c|c|c|c|c|}
\hline Factor & $\begin{array}{c}\text { Number } \\
\text { surviving } 1 \text { year } \\
(n=695)\end{array}$ & $\begin{array}{l}\% \text { surviving } 1 \text { year } \\
\text { from those receiving } \\
\text { chemotherapy }\end{array}$ & $\begin{array}{l}\text { OR 1-year } \\
\text { survival }\end{array}$ & $95 \% \mathrm{Cl}$ & $\begin{array}{l}\text { Adjusted } \\
\text { OR 1-year } \\
\text { survival }\end{array}$ & $95 \% \mathrm{Cl}$ & $\begin{array}{l}\mathrm{P} \text { value } \\
\text { (LR test) }\end{array}$ \\
\hline \multicolumn{8}{|l|}{ Sex } \\
\hline Female & 404 & 45.3 & 1 & & 1 & & \\
\hline Male & 291 & 33.5 & 0.61 & $0.50-0.73$ & 0.61 & $0.48-0.76$ & $<0.01$ \\
\hline \multicolumn{8}{|l|}{ Age group } \\
\hline$<60$ & 150 & 45.2 & 0.79 & $0.62-1.01$ & 1 & $0.74-1.35$ & \\
\hline $60-79$ & 498 & 39.4 & 1 & & 1 & & \\
\hline$\geq 80$ & 47 & 28.3 & 0.48 & $0.32-0.72$ & 0.74 & $0.45-1.21$ & $0.53^{*}$ \\
\hline \multicolumn{8}{|l|}{ Townsend quintile } \\
\hline Least deprived- 1 & 97 & 44.7 & 1 & & 1 & & \\
\hline 2 & 108 & 37.2 & 0.73 & $0.51-1.05$ & 0.8 & $0.52-1.22$ & \\
\hline 3 & 142 & 39.1 & 0.79 & $0.57-1.12$ & 1.02 & $0.68-1.53$ & \\
\hline 4 & 185 & 41.3 & 0.87 & $0.63-1.21$ & 1.01 & $0.68-1.50$ & \\
\hline Most deprived- 5 & 163 & 36.8 & 0.72 & $0.52-1.00$ & 0.88 & $0.59-1.31$ & 0.61 \\
\hline \multicolumn{8}{|l|}{ Performance status } \\
\hline 0 & 196 & 54.9 & 1 & & 1 & 1 & \\
\hline 1 & 307 & 44.2 & 0.65 & $0.50-0.84$ & 0.71 & $0.53-0.97$ & \\
\hline 2 & 119 & 28.9 & 0.33 & $0.25-0.45$ & 0.44 & $0.31-0.63$ & \\
\hline 3 & 24 & 16.7 & 0.16 & $0.10-0.27$ & 0.29 & $0.17-0.51$ & \\
\hline 4 & 1 & 7.7 & 0.07 & $0.01-0.53$ & 0.05 & $0.00-0.63$ & \\
\hline Missing & 48 & 34.3 & 0.43 & $0.29-0.64$ & 0.46 & $0.29-0.75$ & $<0.01$ \\
\hline \multicolumn{8}{|l|}{ Charlson comorbidity index } \\
\hline 0 & 240 & 45.4 & 1 & & 1 & & \\
\hline 1 & 193 & 52.6 & 1.34 & $1.02-1.74$ & 1.42 & $1.03-1.96$ & \\
\hline $2-3$ & 128 & 37 & 0.71 & $0.54-0.93$ & 0.84 & $0.60-1.17$ & \\
\hline$\geq 4$ & 134 & 25.8 & 0.42 & $0.32-0.54$ & 0.75 & $0.55-1.01$ & $<0.01$ \\
\hline \multicolumn{8}{|l|}{ Stage } \\
\hline Limited & 381 & 60.7 & 1 & & 1 & & \\
\hline Extensive & 286 & 26.2 & 0.23 & $0.19-0.29$ & 0.3 & $0.23-0.39$ & \\
\hline Missing & 28 & 66.7 & 1.3 & $0.67-2.51$ & 1.54 & $0.72-3.28$ & $<0.01$ \\
\hline \multicolumn{8}{|l|}{ Chemotherapy } \\
\hline Carboplatin+ etoposide & 530 & 38.4 & 1 & & 1 & & \\
\hline Cisplatin + etoposide & 133 & 67.9 & 3.39 & $2.46-4.66$ & 1.48 & $0.99-2.21$ & \\
\hline CAV & 1 & 20 & 0.4 & $0.04-3.60$ & 0.64 & $0.05-8.59$ & \\
\hline Other & 11 & 34.4 & 0.84 & $0.40-1.76$ & 1.4 & $0.61-3.24$ & \\
\hline Single platinum & 14 & 11.1 & 0.2 & $0.11-0.35$ & 0.42 & $0.23-0.79$ & \\
\hline Missing & 6 & 27.3 & 0.6 & $0.23-1.55$ & 1.06 & $0.33-3.41$ & 0.02 \\
\hline \multicolumn{8}{|l|}{ Chemotherapy cycles received } \\
\hline $\begin{array}{l}\text { More than planned } \\
\text { (mean } 5 \text { cycles) }\end{array}$ & 16 & 53.3 & 0.89 & $0.41-1.93$ & 0.9 & $0.36-2.27$ & \\
\hline $\begin{array}{l}\text { Less than planned } \\
\text { (mean } 3 \text { cycles) }\end{array}$ & 275 & 32 & 0.37 & $0.27-0.50$ & 0.47 & $0.32-0.68$ & \\
\hline 4 planned and received & 115 & 56.1 & 1 & & 1 & & \\
\hline 6 planned and received & 203 & 52.5 & 0.86 & $0.61-1.21$ & 1.22 & $0.82-1.83$ & \\
\hline $\begin{array}{l}\text { Received planned amount } \\
\text { excluding } 4 \& 6 \text { cycles } \\
\text { (mean } 2 \text { cycles) }\end{array}$ & 27 & 28.4 & 0.31 & $0.18-0.52$ & 0.36 & $0.18-0.72$ & \\
\hline Missing planned cycles & 59 & 32.1 & 0.37 & $0.24-0.56$ & 0.45 & $0.28-0.74$ & $<0.01$ \\
\hline \multicolumn{8}{|l|}{ Received radiotherapy } \\
\hline Did not receive radiotherapy & 269 & 27.8 & 1 & & 1 & & \\
\hline Radical ( $\geq 40$ Gy) & 233 & 77.4 & 8.91 & $6.58-12.09$ & 2.94 & $2.04-4.25$ & \\
\hline Palliative (<40 Gy) & 193 & 39.3 & 1.69 & $1.34-2.12$ & 1.43 & $1.10-1.87$ & $<0.01$ \\
\hline \multicolumn{8}{|l|}{ Received PCl } \\
\hline No & 469 & 33.6 & 1 & & 1 & & \\
\hline Yes & 226 & 61.9 & 3.21 & $2.53-4.08$ & 2.08 & $1.54-2.79$ & $<0.01$ \\
\hline
\end{tabular}

$¥:$ LR test for trend. Adjusted OR for all other factors in table. 
Table S2 Sensitivity analysis of 1-year survival with different radiotherapy thresholds for limited stage SCLC

\begin{tabular}{|c|c|c|c|c|c|c|c|}
\hline Radiotherapy received & $\begin{array}{c}\text { Number } \\
\text { surviving } 1 \text { year }\end{array}$ & $\begin{array}{c}\text { Proportion surviving } \\
1 \text { year from all } \\
\text { who received } \\
\text { chemotherapy }\end{array}$ & $\begin{array}{l}\text { OR 1-year } \\
\text { survival }\end{array}$ & $95 \% \mathrm{Cl}$ & $\begin{array}{l}\text { Adjusted } \\
\text { OR 1-year } \\
\text { survival }\end{array}$ & $95 \% \mathrm{Cl}$ & $\begin{array}{c}\mathrm{P} \text { value } \\
\text { likelihood ratio } \\
\text { rest }\end{array}$ \\
\hline \multicolumn{8}{|l|}{ Received radiotherapy } \\
\hline Did not receive radiotherapy & 119 & 44.2 & 1 & - & 1 & - & $<0.01$ \\
\hline Radical ( $\geq 40$ Gy) & 197 & 81.4 & 5.52 & $3.69-8.26$ & 3.32 & $2.07-5.31$ & \\
\hline Palliative (<40 Gy) & 65 & 55.6 & 1.58 & $1.02-2.44$ & 1.53 & $0.94-2.49$ & \\
\hline \multicolumn{8}{|l|}{ Received radiotherapy } \\
\hline Did not receive radiotherapy & 381 & 44.2 & 1 & - & 1 & - & $<0.01$ \\
\hline Radical ( $\geq 30$ Gy) & 236 & 77.6 & 4.37 & $3.15-6.28$ & 2.83 & $1.84-4.34$ & \\
\hline Palliative (<30 Gy) & 26 & 47.3 & 1.13 & $0.63-2.02$ & 1.31 & $0.69-2.47$ & \\
\hline
\end{tabular}

Odds ratios are adjusted for sex, age, social deprivation, PS, comorbidity, receipt of PCl, chemotherapy regimen and cycles.

Table S3 Characteristics of individuals receiving chemotherapy who had limited stage

\begin{tabular}{|c|c|c|c|c|c|}
\hline \multirow{2}{*}{ Factor } & \multicolumn{2}{|c|}{ Received 4 cycles } & \multicolumn{2}{|c|}{ Received 6 cycles } & \multirow{2}{*}{$\begin{array}{c}\mathrm{P} \text { value for differences between } \\
\text { treatment groups }\left(\mathrm{chi}^{2}\right)\end{array}$} \\
\hline & Number & Percentage & Number & Percentage & \\
\hline \multicolumn{6}{|l|}{ Sex } \\
\hline Male & 40 & 44 & 57 & 48 & 0.53 \\
\hline Female & 51 & 56 & 61 & 52 & \\
\hline Age (median \& IQR) & \multicolumn{2}{|c|}{$69(60-75)$} & \multicolumn{2}{|c|}{$67(60-73)$} & 0.60 (t test) \\
\hline \multicolumn{6}{|l|}{ Performance status } \\
\hline 0 & 29 & 32 & 30 & 25 & 0.57 \\
\hline 1 & 42 & 46 & 52 & 44 & \\
\hline 2 & 13 & 14 & 20 & 17 & \\
\hline 3 & 1 & 1 & 4 & 3 & \\
\hline Missing & 6 & 7 & 12 & 10 & \\
\hline \multicolumn{6}{|c|}{ Charlson comorbidity score } \\
\hline 0 & 35 & 38 & 30 & 25 & 0.12 \\
\hline 1 & 26 & 29 & 50 & 42 & \\
\hline $2-3$ & 21 & 23 & 24 & 20 & \\
\hline 4 & 9 & 10 & 14 & 12 & \\
\hline \multicolumn{6}{|l|}{ Socioeconomic status } \\
\hline 1-Least deprived & 14 & 15 & 18 & 15 & 0.89 \\
\hline 2 & 15 & 16 & 20 & 17 & \\
\hline 3 & 16 & 18 & 21 & 18 & \\
\hline 4 & 25 & 27 & 26 & 22 & \\
\hline 5-Most deprived & 21 & 23 & 33 & 28 & \\
\hline
\end{tabular}


Table S4 Characteristics of individuals receiving chemotherapy who had extensive stage

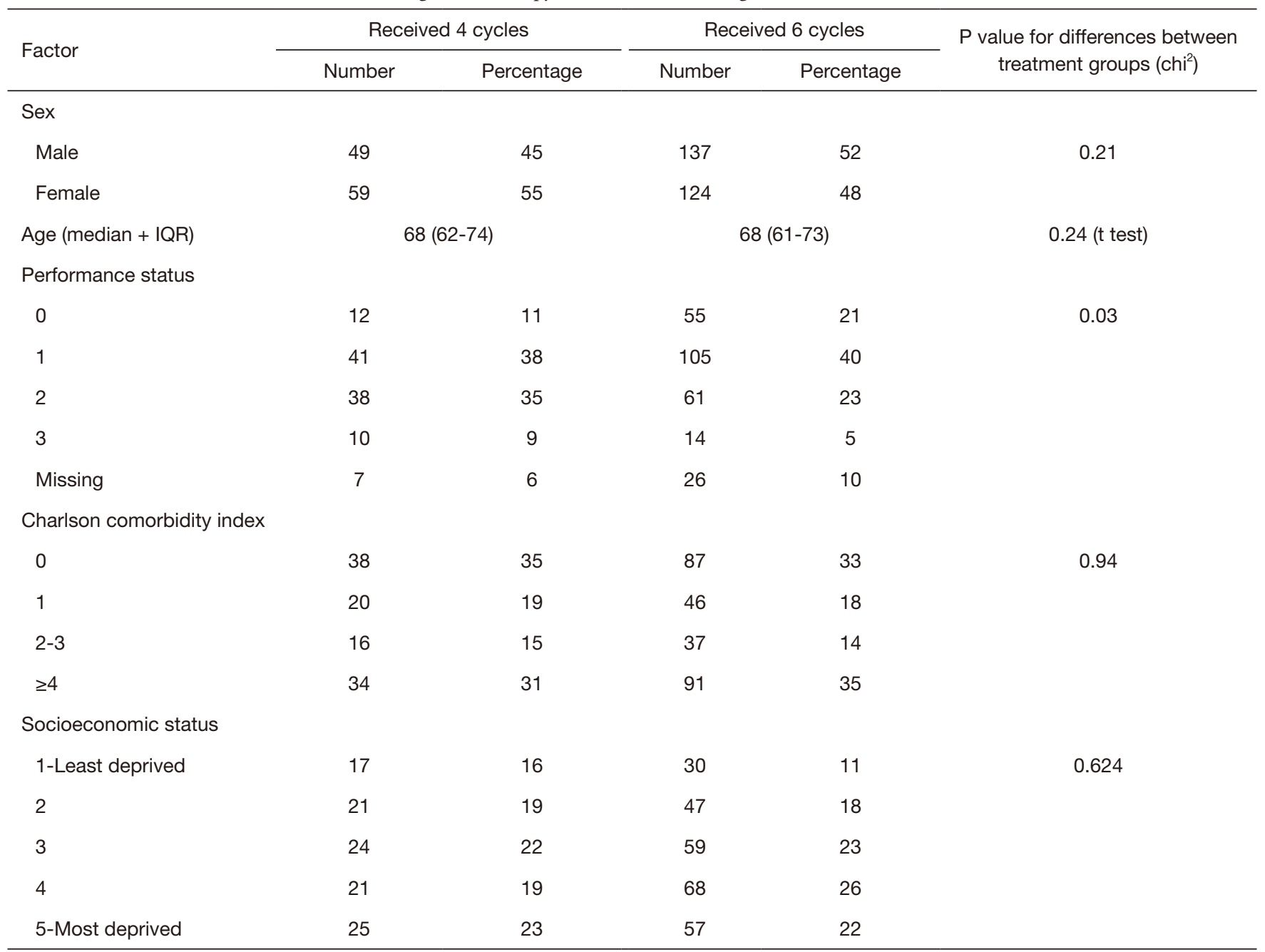


Table S5 Characteristics of individuals receiving PCI who had extensive stage

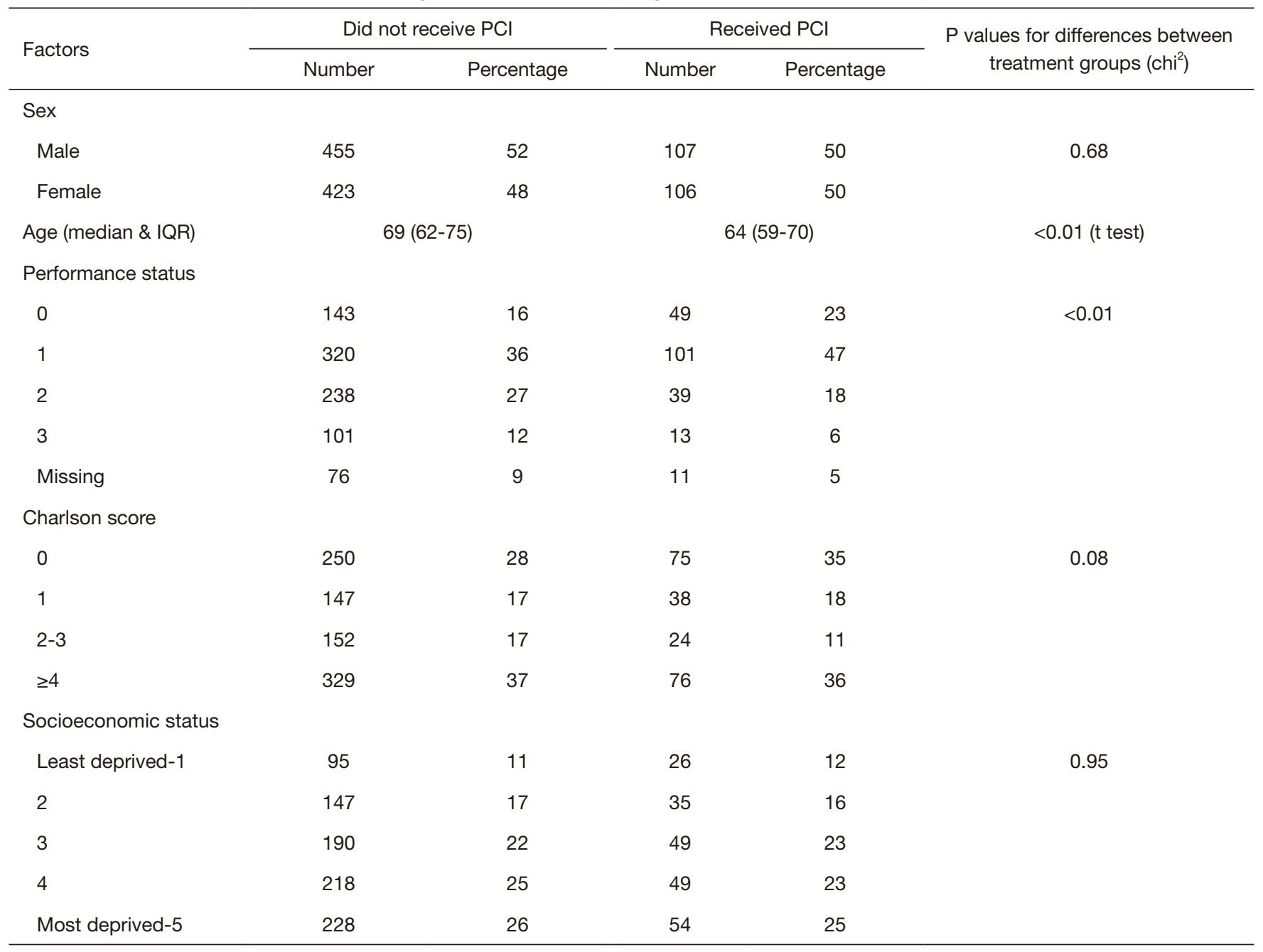


Table S6 Characteristics of individuals receiving radiotherapy who had extensive stage

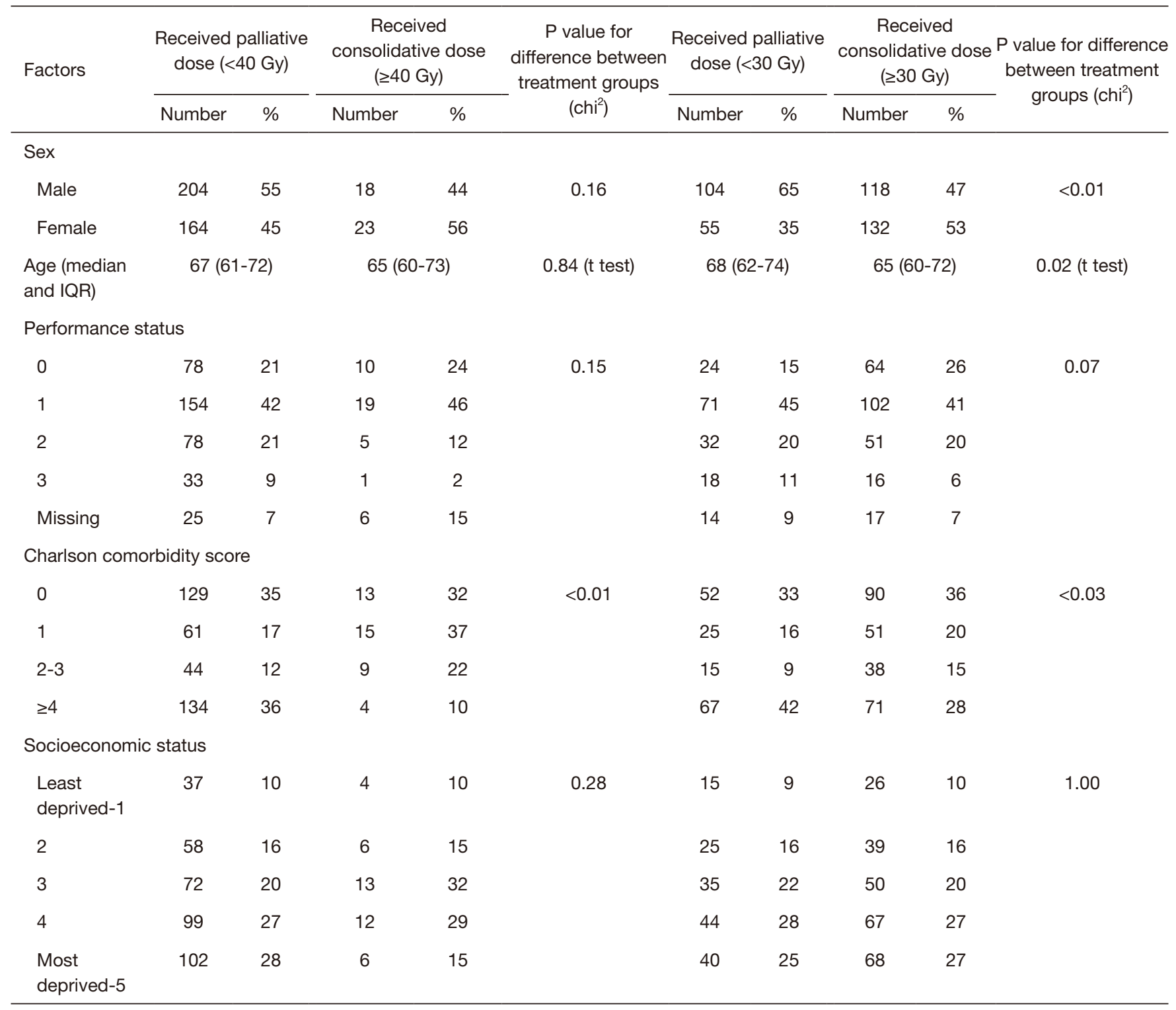

